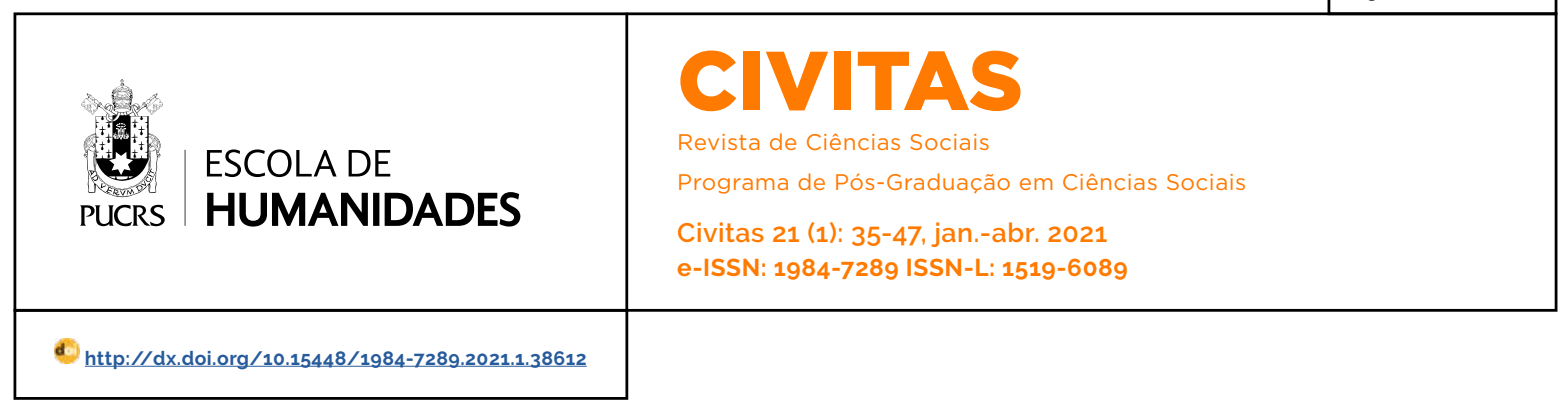

DOSSIÊ: TEORIA SOCIAL E SOCIOLOGIA EXISTENCIAL

\title{
Possiveis contribuições da fenomenologia e da etnometodologia para uma sociologia dos esportes coletivos
}

\author{
Possible contributions of phenomenology and ethnomethodology to a sociology of \\ team sports \\ Posibles contribuciones de la fenomenología y etnometodologia a una sociología de \\ los deportes de equipo
}

Eduardo Fernandes Nazareth ${ }^{1}$ orcid.org/0000-0002-0538-8337 eduardo.nazareth@gmail.com

Recebido em: 16 jul. 2020. Aprovado em: 16 out. 2020. Publicado em: 07 maio. 2021.

\section{(c) (1)}

Artigo está licenciado sob forma de uma licença Creative Commons Atribuição 4.0 Internacional.
Resumo: Grande parte dos trabalhos em sociologia do esporte é profundamente marcada pela obra de dois importantes autores, Norbert Elias e Pierre Bourdieu. O presente artigo pretende explorar as potenciais contribuições que as obras de Schutz e de Garfinkel podem trazer aos estudos do esporte. Embora esses autores não tenham se dedicado propriamente ao tema, suas obras podem ser úteis à construção de uma perspectiva que revele certos aspectos do fenômeno esportivo ainda a serem explorados considerando-se a constituição da experiência de jogar no mundo vivido dos jogos esportivos coletivos.

Palavras-chave: Fenomenologia. Etnometodologia. Esportes coletivos. Experiência. Teoria sociológica.

Abstract: Much of the work in sociology of sport is deeply marked by the work of two important authors, Norbert Elias and Pierre Bourdieu. The present article intends to say that Schutz and Garfinkel, although their works were not dedicated to sports, can bring relevant contributions to the construction of a perspective that reveals certain aspects of the sports phenomenon yet to be explored from the constitution of the experience of playing in front of the world lived from collective sports games.

Keywords: Phenomenology. Ethnomethodology. Collective sports. Experience. Sociological theory.

Resumen: Gran parte del trabajo en sociologia del deporte está profundamente marcado por el trabajo de dos importantes autores, Norbert Elias y Pierre Bourdieu. El presente artículo pretende resaltar que Schutz y Garfinkel, si bien sus trabajos no fueron dedicados al deporte, pueden aportar aportes relevantes para la construcción de una perspectiva que revele ciertos aspectos del fenómeno deportivo aún por explorar desde la constitución de la experiencia de jugar frente a del mundo vivido de los juegos deportivos colectivos.

Palabras clave: Fenomenología. Etnometodología. Deportes colectivos. Experiencia. Teoría sociológica.

\section{Introdução}

Um número expressivo de trabalhos em sociologia do esporte é profundamente marcado pela obra de Norbert Elias e de Pierre Bourdieu. Justamente por articularem uma compreensão sociológica acerca da prática esportiva com teorias reconhecidas e consistentes acerca da sociedade moderna, as perspectivas dos dois autores influenciaram for- 
temente a definição dos temas e as abordagens sociológicas relacionadas ao esporte.

As perspectivas de Elias e de Bourdieu possibilitaram aos pesquisadores valiosos recursos conceituais que, no entanto, deixam em um plano secundário questões que poderiam ser igualmente relevantes ao entendimento do fenômeno esportivo. O presente artigo pretende destacar que autores que promoveram ou incorporaram a Fenomenologia em suas obras, como Alfred Schutz e Harold Garfinkel, embora não tenham se dedicado propriamente ao esporte, podem trazer contribuições relevantes à construção de uma perspectiva propriamente sociológica para o fenômeno esportivo.

\section{Deslocamento da centralidade: do macro para o microssocial}

O que há de comum entre as perspectivas de Elias e de Bourdieu² é que ambas constroem o esporte como um problema sociológico a partir de sua relação com dinâmicas sociais mais abrangentes, com uma estrutura social mais ampla. Essa estrutura se projeta sobre os agentes ou sobre as situações de modo determinante, voltando o olhar sociológico para além das ações, das intenções e da consciência desses agentes no campo de jogo. Tal abordagem, embora reveladora, parece deixar pouco a ser compreendido em relação à constituição dos encontros humanos, à gestão situada das interações por parte dos agentes, à emergência endógena às situações de uma ordem e ao um universo intersubjetivo relacionado à experiência de jogar.

Ao mobilizar referências de autores como Schutz e Garfinkel, espero demonstrar que suas contribuições à teoria sociológica podem ser úteis no sentido de gerar um quadro teórico no âmbito do qual se evidencie outra ordem de fenômenos sociais relacionados ao esporte, além dos que já foram destacados pelas obras de Elias e de Bourdieu. Trata-se aqui da proposição de uma perspectiva voltada para dentro da disputa do jogo, para sua cena, para seu desenrolar e, sobretudo, para a dimensão intersubjetiva da experiência da relação competitiva em esportes coletivos como o futebol, o basquetebol entre outros esportes coletivos.

Nesse sentido, situamos a problemática esportiva sobre a constituição coletiva da experiência de jogar e sobre o mundo que se presentifica entre os participantes. A abordagem proposta pode revelar aspetos da relação entre a experiência de jogar, capturada na ambiência da ação, em seu estado afetivo particular, sob um ordenamento prático-ontológico próprio dos jogos esportivos coletivos.

A fenomenologia pode ser muito útil no encaminhamento de uma perspectiva adequada aos propósitos apresentados na medida em que ela se ocupa da constituição intersubjetiva do mundo social, suas diversas regiões ou setores, vistos como ambiência da fantasia (do sonho, das estórias, das brincadeiras) ou da realidade cotidiana (Schutz 1967b, 207-59). O mundo e suas diversas regiões são entendidos aqui como ordens ou subordens de existência (Gurwitsch 1957, 169). Tudo e todos se encontram a partir de modos ontologicamente inter-relacionados e codeterminados de ser, isto é, a partir de uma ontologia constitutiva de um mundo a ser vivido agora em uma ocupação viva, real. A esses modos próprios de ser corresponde certa atitude natural dotada de características próprias, sedimentando tais ontologias no senso comum, sendo mais ou menos compartilhados e em relação aos quais a ação adquire sentido e densidade afetiva.

Para elaborar uma nova perspectiva para o fenômeno esportivo - assim como para qualquer fenômeno social que envolva uma prática comum em simultaneidade e copresença -, considera-se que cabe ao sociólogo, inicialmente, compreender como esse mundo se constitui e se apresenta socialmente aos participantes, conformando uma ontologia própria em relação à qual um sentido existencial determina as condições de possibilidade para a experiência, nesse caso, de jogar

\footnotetext{
2 A perspectiva de Elias volta-se para a relação entre o esporte e o processo civilizador moderno (Elias 1993; 1994; Elias e Dunning 1992) e a de Pierre Bourdieu, para o esporte e sua relação socialmente estruturada com o habitus de classe, de gênero, com a lógica dos campos e com o poder simbólico (Bourdieu 1983; 1987; 1990; 2002; 2007).
} 
coletivamente; pois é diante da ordem do mundo a que se refere a presente ocasião que se coloca aos agentes que se constitui o curso do tempo imanente da experiência da ação, em que o ser se move mobilizando consigo os elementos desse mundo.

É à essa experiência que, segundo Schutz (1967a), o sociólogo deve estar atento para realizar o anseio weberiano de buscar o sentido subjetivamente visado da ação social. Os mundos, as ideações, os procedimentos intersubjetivos seriam constitutivos dessa realidade, que, desse modo, torna-se uma realidade social.

Nesse sentido, a etnometodologia, e especialmente a obra de Garfinkel, nos apresenta uma perspectiva interessante. Ela orienta nosso olhar a como a sociedade - essa generalização problemática - resulta da própria resolução ordinária de problemas cotidianos por parte dos próprios indivíduos, membros competentes na gestão de seus assuntos comuns. Garfinkel $(1967,2002)$ volta-se justamente à seguinte questão: como a ordem social se apoia no exercício de competências práticas dos membros de uma sociedade na administração em comum das situações da vida cotidiana, isto é, na gestão da ordem social? Em outras palavras, Garfinkel orienta nosso olhar para o modo como os agentes mobilizam os conhecimentos de senso comum, que eles dominam em seu sentido prático, e a como os orientam ao exercício rotineiro e naturalizado de procedimentos intersubjetivos, tidos como autoevidentes, constitutivos do real e da própria sociedade. Baseados na confiança reciproca (Garfinkel 1963) de que, enquanto membros dominam a competência para administrar situações reais, eles administram a ordem social espontânea e naturalmente.

Para este autor, a ordem dessas atividades cotidianas é concebida como uma ordem endogenamente produzida, que deve ser observada e compreendida do seu ponto de vista factual, em sua produção viva e situada, a partir da ação dos envolvidos, pois é aí que a ordem social e a sociedade - ou a ordem normativa do jogo ou o jogo - efetivamente se produzem de acordo com um padrão de normalidade que vigora na comunidade de membros (membros praticantes competentes).
As bases deste padrão podem ser revisitadas pelos membros, caso a situação evidencie disparidades em relação às expectativas. As situações emergem e são sempre administradas pelos agentes a partir do exercício situado de suas competências - no nosso caso, jogadores e árbitros. Para Garfinkel, portanto, a ordem não está em um mundo pré-interpretado, e nessa medida predeterminado por uma entidade transcendente que paira acima dos indivíduos (como a sociedade, nos termos durkheimianos). A ordem está em um mundo continuamente produzido e reproduzido agora pelos agentes na imanência de uma atividade comum, mesmo que eles não saibam disso nesses termos.

A ideia de transcendentalidade ou de imortalidade na perspectiva de Garfinkel é entendida como a sintese mais ou menos estável de experiências vividas em comum, convertidas em um padrão de normalidade, em expectativas relacionadas a uma ordem de atividade e em saberes práticos de acordo, que se apresentam e penetram os indivíduos envolvendo suas consciências, seus afetos, seus corpos, como um todo componivel com o ambiente, gerando potencialidades existenciais diante de um mundo prático compartilhado. Nesse sentido, os conceitos de transcendentalidade ou de imortalidade são usados por Garfinkel

\begin{abstract}
para falar de ocupações humanas com base nas quais os membros, estando em meio à organização das coisas [organizational things], sabem, a partir dessas coisas em meio às quais estão, que elas os precedem e que estarão lá depois que partirem. Imortal é uma metáfora para a recorrência da sociedade ordinária, [...] produzida, observada, observável, local e naturalmente descrita [accoutable] em e a partir de uma 'reunião de hecceidades. (Garfinkel 2002, 92, tradução nossa)
\end{abstract}

Aplicando a proposição ao nosso objeto, podemos dizer que o espaço do jogo e seus objetos estão ali, entre os jogadores, no ambiente da partida em curso ou prestes a se iniciar. Podemos entrar e sair do mundo do jogo porque o jogo é essa atividade que é, ao mesmo tempo, mundo imortal e transcendente, onde nos situamos quando queremos jogar e onde vivemos as 
experiências concretas de nossas disputas, isto é, um mundo que se constituiu pela recorrência das experiências práticas, pelas intervenções modeladoras da forma de uma disputa e pela constituição de padrões referenciais.

Nesse sentido, de certa maneira, o caráter mais factual da realidade que se produz aqui e agora, tributária de uma ordem transcendente, distingue a perspectiva etnometodológica da fenomenológica. Para a Etnometodologia, por um lado, a realidade deve ser compreendida a partir do modo como os agentes, prospectivamente, a sustentam e a vivenciam originariamente, no exercicio vivo de uma competência prática comumente testemunhada, inteligivel, congruente, real. Todavia, por outro lado, a realidade deve ser também compreendida retrospectivamente, em um plano reflexivo, em que a realidade vivida se torna questionável, relatável, descritivel, reprodutivel, ensinável, suscetivel a cobranças e justificações (accountable) e, nessa medida, modificável em seus pressupostos aplicáveis a experiências futuras - ao que se referem mudanças nas regras do jogo, sejam elas as regras básicas, as et cetera ou as do modo escolhido de jogar (Garfinkel 1963). Desta forma, a imortalidade e a transcendentalidade do jogo, como prática normal e esperada e como mundo (suas regras formais ou não escritas), assim como de qualquer ordem normativa, são suscetiveis à reconstituição dos termos em que se recolocam aos agentes.

\section{Uma perspectiva fenomenológica para os jogos esportivos}

É imprescindivel compreender o esporte como um jogo agonístico (Caillois 1994). ${ }^{3}$ Os jogos agonisticos constituiram-se em espaços práticos à parte do mundo da vida cotidiana (Schutz 1967b, 207-59) nos quais entra em questão o reconhecimento, por si mesmo e por parte dos demais, acerca da própria condição de membro praticante, e a conquista da estima e do valor como bom competidor ou bom jogador desse jogo.

Trata-se de um espaço lúdico de livre adesão para os seres humanos demonstrarem suas capacidades em um jogo, o limite a que podem chegar para se provarem em uma disputa agônica absorvente, de vitória ou de derrota, de glória ou de fracasso, onde o sentido de vida ou de morte ressurge ontologicamente modificado.

As próprias competências e disposições relacionadas ao jogo são postas à prova diante de outros praticantes (membros competentes) em situações de disputa acirrada e de prova, de onde se pode entrever um fundo de seriedade no divertimento que então se obtém do arrebatamento, tornando tal prática profundamente significativa para os envolvidos.

Assim, é a própria organização humana da disputa - que designamos por jogo - que sustenta essa atividade real bem como seu fundo de significação. É ela que se torna capaz de manter diante dos competidores, continuamente, enquanto dura a partida, o tentador convite ou o chamado avassalador para lançar mão de suas habilidades, para recrutar ao máximo suas energias, a fim de superar os desafios que então se colocam entre os jogadores.

Aquele reconhecimento e a prova de ser um bom ou o melhor ocorrem na medida em que os feitos que se realizem em uma disputa nesse ou naquele jogo agonistico sejam percebidos como resultado direto das capacidades mais próprias dos competidores. Nesse sentido, para que esse espaço lúdico de experiência - esse mundo - possa se constituir, é necessário que uma forma da competição possa sustentar concretamente uma disputa esportiva. Assim, instaura-se um campo de discussão acerca das necessidades lúdicas e agonísticas no âmbito de uma formalidade prática, tendo em vista que as intensidades afetivas agônicas devam surgir e ressurgir com base em um padrão de normalidade referencial entre os jogadores.

Há, por exemplo, a necessidade de interdependência solidária entre dimensões da experiência

\footnotetext{
3 Para Roger Caillois (1994), os jogos podem assumir algumas formas particulares que predominam mais ou menos de acordo com o contexto cultural em que surgem e subsistem. Eles são compreendidos como formas em que se impõem mais ou menos principios como o da simulação (mimicry), o da vertigem (ilinx), o da sorte (alea) ou o da competência (agon). Nos tempos modernos, argumenta o autor. destacam-se os jogos agon; a racionalidade, o cálculo, o mérito e a competitividade haviam se constituido em valores predominantes.
} 
humana que, integradas, possam dar existência e duração à disputa. Isso é imprescindivel para que o surgimento daquela força agonística imanente às coletividades e individualidades possa nascer e ser revivida.

O caráter desafiador dessas ocasiões deve propor aos participantes uma atividade que, aproximando-os e contrapondo-os, ofereça-lhes a oportunidade de que encontrem um ser próprio que se disponha a transcender a si mesmo a fim de que realizem extraordinários e grandes feitos.

Nesse sentido, a atividade deve se sustentar sob um mesmo enquadramento, implicando um complementar e pré-pessoal lançar-se à disputa em um modo de ser agonístico, incorporado e espacializado, nessa zona de experiência nossa, sobre o mundo transcendente e imortal do jogo, enquanto os seres dos jogadores se sobrepõem, se compõem e se unificam em uma ou outra equipe sob eixos definidos pelo jogo.

A potencialidade de arrebatamento desses jogos esportivos coletivos é tal que pode ser espantoso ao observador mais atento a maneira como a dinâmica gerada por uma partida mantém os participantes completamente imersos nessa zona comum de experiência que se conforma com a orientação a um nós (Schutz 1967a, 163-167) a que o desafio agonístico os lança e que então se mostra como parte de uma atitude natural.

A disputa na qual consiste essa atividade se caracteriza por uma lógica prática capaz de sustentar nosso engajamento, nossa atenção e de nos tornar intensamente concentrados em nós mesmos, ao curso da nossa ação coletiva, no nosso movimento, enquanto a relação competitiva se constitui e ganha profundidade temporal até o fim da partida.

O fenômeno que salta aos olhos, e que julgo como central em relação ao jogo, é justamente como esse se torna capaz de atrair os envolvidos inteiramente à partida, a esse nós mesmos da disputa, ao seu aqui e agora, e continuamente até o seu fim, em uma experiência íntegra, total e prática. Para que isso seja compreensivel, é preciso considerar que há aqui um conjunto de elementos organizados por uma lógica prática.

Essa lógica prevê, por um lado, a conformação de um mesmo ambiente para disputas corporais, isto é, passivel de ser integrado na prática e existencialmente na simultaneidade existencial do espaço vivido e na sucessão temporal de uma mesma corrente imanente de eventos total e bem delimitada por agentes em ações mutuamente referidas com seus corpos. Por outro lado, essa lógica prevê posições a serem ocupadas e funções a serem desempenhadas pelos jogadores constituindo uma disputa que seja minimamente desafiadora e que se prolongue de modo excitante e absorvente, produzindo e atualizando, durante o tempo da partida, o efeito de atrair, envolver e interligar a todos entre si, em uma espécie de complexo interativo.

Deve possibilitar disputas intensas que comportem, nas ações, fluxos de energia e um nivel superior de agressividade, mantendo-se, entretanto, sob o controle das regras. Desse modo, a atividade agonística mostra-se capaz de arrebatar todo o ser em sua profundidade inclusive inconsciente, na espiral competitiva de uma disputa ao permitir a entrega total ao exercicio mais pleno das próprias forças, competências e habilidades requeridas pelo oponente nos termos da disputa.

O participante pode, então, ser arrebatado na atividade, que o impulsiona a assumir um característico modo próprio de ser jogador. Como se pode notar, esse ser é vivenciado em sua totalidade em relação à organização do desafio, em função do qual se estabelece um eixo espaço-temporal e uma economia das energias e dos afetos. Isto é, todo o conjunto prático em que o ser se insere implica uma estrutura existencial que se apresenta em relação a um mundo e à sua ordem ontológica que é constituinte da facticidade dessa experiência (Heidegger 2005,95 ) e que, no nosso caso, é marcado sobremaneira por um sentido de desafio.

A atitude pessoal de superação desse desafio atual, na medida em que este se encadeia no tempo com outros, se refere à conformação, sob a ordem do jogo, de um desafio total que se coloca entre nós, jogadores, em uma partida. Os envolvidos se lançam integralmente à ação e a existência então transcorre no tempo por uma dinâmica de fluxos, de retenções e descargas de energia, mobilizando as emoções, o corpo, a percepção e a cognição, em um só conjunto existencial, em 
uma só experiência (Dewey 1974, 249), em uma só totalidade com o mundo ao redor (Gurwitsch 1979 , 38), com o outro, nas mesmas situações.

Assim, o jogo ordena a existência de todos, do início ao fim da disputa, fazendo convergir e fundir interior e exterior em uma mesma experiência na qual todos propriamente são uns com os outros e com o mundo, prendendo vivamente o jogador ao jogo por uma espécie de visgo existencial enquanto dura o desafio da partida, possibilitando uma relação singular de autenticidade e de totalidade nesse modo de ser.

Se comparada com a experiência da vida cotidiana, fragmentada, dispersa, sem sentido, a organização da atividade de jogar produz sobre a experiência uma tal concentração e um tal alinhamento extraordinário e total do ser incorporado com o mundo do jogo esportivo que, ao se caracterizar por esse aspecto de integração e ordem distinto e marcante - sendo, por isso, também dotada de aspectos estéticos de delimitação, proporção, ritmo e harmonia - ao fim, posso dizer vivi "uma experiência", como bem conceituou Dewey $(1974,247)$. E é essa experiência que seduz muitos de seus praticantes mais aficionados. Mas como podemos avançar na compreensão de como essa experiência é possivel?

\section{Condições para a compreensão do mundo do jogo: imanência e transcendência}

Na tentativa de responder à pergunta acima, levanto a hipótese de que a forma prática da atividade, uma forma imortal ou transcendental, possui uma história cujo propósito e determinação são e foram o de gerar as condições para que se vivesse a experiência extraordinária da prática dos esportes. ${ }^{4}$ Nesse sentido, se colocam outras duas questões. Quais objetivos foram perseguidos para que se chegasse à forma convencional básica dos esportes coletivos? Como os mundos dos esportes coletivos produzem essa experiência?
Tais perguntas pressupõem que deve haver alguns traços de uma organização prática transcendental a fim de que se produzam as disputas propriamente agonísticas e se potencializem seus efeitos característicos de maneira imanente à prática. Este arranjo é necessário para que a ocasião de uma disputa se configure e se sustente no tempo-espaço intersubjetivo dos jogadores. Essa organização é também um processo de relativa estabilização de um mundo prático e se refere a uma estrutura lógica fundamental que corresponde a certas determinações pré-ontológicas inerentes a esse ente histórico agonístico, o jogo esportivo. Assim, as várias formas práticas especificas que assume (o rúgbi, o futebol, o handebol, o basquetebol etc.) constituiram-se em mundos nos quais podemos vivenciar a experiência de jogar coletivamente.

O que quero dizer é que o mundo do jogo não é apenas a pura imanência da disputa. Ele se apoia em uma forma que se sedimentou como uma prática e que configura a ordem para uma relação competitiva típica com certas características, provendo engajamento dos jogadores na cadeia de ação e reação, gerando excitação, arrebatamento e continuidade.

Nesse sentido, o que chamo forma transcendental do jogo constitui as bases lógicas para uma estrutura interativa dinâmica predisposta a gerar adesão a uma situação problemática que se constitui como tal entre os jogadores. Essa situação os envolve aqui e agora se encadeando na sucessão de novas situações problemáticas, impondo assim, pouco a pouco, o envolvimento em uma zona de experiência coletiva na qual submergem em um modo prático que requer inserção ativa, incorporada, total, mais ou menos dominada pela consciência.

Do ponto de vista mais formal e fundamental de delimitação de um sistema prático, essa forma deve:

\footnotetext{
4 Não pretendemos aqui reconstituir essa história, pois seus fatores sociológicos determinantes foram em grande medida explorados por Elias e Bourdieu nas obras citadas neste artigo. Nem é possivel explicar inteiramente a história dos esportes a partir dessa ordem de fenômenos práticos geridos pelos membros em uma cena. Ainda que a produção autóctone de sentido em grande medida se dê a partir da gestão localizada e endógena das situações, as dinâmicas de ordem institucional (federações e confederações), política (estados nacionais e empresas) e de produção global de sentido (imprensa, universidades etc.) devem ser, evidentemente, mais bem exploradas de um ângulo sociológico mais abrangente que contemple de forma mais precisa as várias controvérsias em torno do jogo.
} 
1. Deixar os competidores com seus recursos e suas habilidades diante de adversidades que o próprio contexto competitivo deve produzir, isolando a disputa da interferência de fatores do mundo exterior;

2. Determinar uma disputa por algo, tornando imprescindivel o esforço e dispêndio extraordinário de energia;

3. Basear essa disputa na igualdade e no equilibrio formal entre as partes;

4. Primar pela construção gradual e justa do resultado da partida já que a percepção de igualdade formal e de justiça na determinação do melhor é imperativo ao engajamento;

5. Prover as condições mínimas para a aplicação das regras que suportarão essa formalidade justa.

Assim, cria-se uma atividade à parte, de sentido especificamente agonístico, com o fim de propiciar uma experiência singular, sintonizada com um tempo histórico e com o universo cultural moderno.

Para refinarmos nossa compreensão da geração de uma lógica competitiva nos esportes coletivos em questão, talvez seja necessário incluir outros elementos que se submetem àquelas determinações formais. Os esportes coletivos dependem de um sentido funcionalmente complementar entre os objetos, o espaço e os corpos. Eles devem ser articulados sob uma lógica interativa básica, constituindo uma disputa de domínio prático possivel por parte dos jogadores.

Uma disputa deve surgir de uma configuração que se atualize continuamente a partir de um núcleo interativo de onde se impulsionam adiante no tempo e espaço comuns. A imanência dos acontecimentos depende da ação urgente que esse núcleo de disputa demanda dos jogadores sendo desse ponto do espaço e do tempo da experiência e da ação - o do agora limitado pelo a seguir imediato, projetado adiante no sentido provável do seu fim - que se vive a existência no jogo.

É do modo como tempo e espaço se encontram organizados na prática que se define a sucessão e o sentido de série contínua, marcada por descontinuidades, combinações e recombinações de posição, ao longo de uma partida e de onde a experiência esportiva de desafio retira sentido de unidade, tensão e arrebatamento.

Em ações reciprocamente orientadas, de sentido prático mais preciso, os jogadores se atraem e se organizam em um complexo interativo, envolvendo suas consciências e seus corpos na sucessão e na simultaneidade do tempo imanente dessa disputa.

A atividade interativa depende de que as ações - submetidas à forma lógica do jogo - se baseiem em expectativas congruentes em relação à ação do outro possibilitando a gestão da situação de disputa por parte deles mesmos no exercício de suas competências como jogadores. Sem o compartilhamento de um saber incorporado acerca de como jogar, de um saber seguir a série que a forma estabelece, como diria Wittgenstein (1996, 92), a atividade competitiva não tem existência ou continuidade espaço-temporal.

Assim, para que essa atividade se conserve viva ela precisa, além de definir os termos de um desafio coletivo envolvente, manter e renovar o impeto do jogador e das equipes de se provarem diante do outro em disputas que se coloquem de imediato ao redor de seus corpos, demandando deles ação, interação e exercício de competências próprias.

De alguma maneira, o desafio se conforma ao definir objetivos e interesses contrapostos, de modo que o que uma equipe deve obter o outro deve impedir que o consiga e vice-versa. O desafio deve ser penetrante, abrangente e deve conservar o impulso de ação dos indivíduos em um sentido convergente. Para isso, as ações devem ser orientadas pela forma de modo que as energias orientadas pelas ações promovam sustentação reciproca e impulso de retroalimentação para que a zona intersubjetiva se constitua e se conserve viva, produzindo a força motriz que deve emanar da própria tensão gerada pela disputa.

\section{As funções ontológicas constituintes do mundo do jogo}

O mundo do jogo esportivo deve ser organizado em termos físicos visando estabelecer as condições agonísticas para uma disputa entre os agentes humanos. Nesse sentido, é uma condição imprescindivel ao jogo plasmar um espaço ou 
um cenário onde os jogadores possam realizar suas ações exibindo-se e contrapondo-se reciprocamente como obstáculos, desencadeando uma dinâmica interativa com base no sentido mutuamente orientado dessas ações visando uma meta imediata e um objetivo final.

O ambiente é o fundo para a emergência da figura das ações e interações e, sendo assim, o modelo transcendental de espaço de jogo deve desempenhar a função de prescrição de meio adequado para a interação competitiva. Este modelo deve prever a constituição da dimensão física do desafio, deve apresentar ponto de partida, deve demarcar área contínua bem definida e meta a ser defendida ou a ser alcançada, deve possibilitar um desafio comum aos corpos e às ações além de ser plataforma de exibição dessas ações entre os participantes, possibilitando que a disputa corporal possa efetivamente ocorrer.

Nesse espaço de jogo temos objetos que cumprem funções também constituintes do desafio na medida em que agem sobre os jogadores, como diria Bruno Latour (2012, 106-22). São objetos para identificação dos membros das equipes (os uniformes); para a proteção (capacetes, joelheiras); para garantir corpos melhor ajustados ao ambiente (chuteiras, luvas) e, também, objetos que delimitam o espaço do campo criando ponto de partida, demarcações intermediárias e meta (bandeiras, traves, tabelas, redes).

Entre tais objetos destaca-se aquele que é condicionante central das disputas nos esportes coletivos. Um artefato que se torna capaz de concentrar continuamente as atenções e de condicionar de maneira coordenada as interações em razão de suas propriedades físicas (forma e peso), por ser de controle incerto e imprevisivel aos corpos, por ser fugidia, mas de movimento fluido, regular e, até certo ponto, controlável. Esse objeto é, obviamente, a bola. Para pontuar, os jogadores de uma equipe devem conduzi-la sobre o campo de jogo no sentido da meta, enquanto os da outra equipe devem impedi-la. A bola fica solta no ambiente, está sempre sujeita às forças físicas que atuam sobre ela, é disputada pelos jogadores. Sua capacidade de ser movimentada, mas não inteiramente controlada, é importante para a dinâmica envolvente do jogo.

Em conjunto, as propriedades físicas dos objetos devem se articular solidária e funcionalmente com as propriedades físicas do espaço (ao ar livre, em espaço coberto, piso de areia, de grama, de madeira etc.) e com a capacidade dos corpos de movimento e de percepção conformando o desafio coletivo.

Dentro de certas especificações, espaços e objetos formam uma rede que age simultaneamente sobre os jogadores (sobretudo, seus corpos), aproximando-os e impelindo-os à ação, nos termos de uma disputa coletiva desse ou daquele jogo. Objetos e espaços sustentam o fundo prático comum à configuração física do desafio que se coloca entre os jogadores.

A propósito, todo novo avanço tecnológico que se pretenda incorporar à prática esportiva - um novo material para os objetos ou para o campo de jogo, uma nova tecnologia de contagem ou detecção de movimentos - deve se submeter ou servir ao fim de preservar ou promover o sentido agonístico do encontro esportivo a partir da preservação de uma formalidade justa e equitativa entre os competidores sob pena de se descaracterizar ou de gerar conflitos recorrentes.

\section{A ordem transcendental do jogo}

Entendemos o jogo como organização prática do desafio coletivo, isto é, como lógica transcendental: limite prático constitutivo de uma lógica imanente às disputas. Essa lógica ordena a imanência das interações no que se refere à centralidade do desafio do ponto de vista dos jogadores. Organizados em grandes complexos interativos, os grandes movimentos coletivos realizados pelas equipes em campo se encontram submetidos à forma lógica de toda a disputa.

Esses movimentos evoluem no formato de ataque contra defesa em ações interdependentes, organizadas coletivamente de um ponto inicial de onde progridem em uma sucessão de etapas, passando por pontos intermediários até sua culminância. Essa evolução define os contornos do que chamo unidade interativa que, ao se sucederem, constituem uma partida real de 
dentro dos núcleos de disputa, da sua imanência e sob a lógica do jogo.

Há objetivos imediatamente contrapostos que estruturam a inserção das equipes em uma disputa: de um lado, os jogadores de uma equipe buscam conduzir a bola à meta com passes e movimentos coordenados; de outro lado, os jogadores da equipe adversária tentam fechar os espaços para esse avanço, interromper a ação ofensiva e, se possivel, retomar a bola. Ambos devem agir dentro do que a regra permite. Geralmente, a forma do jogo prima por um equilibrio entre ataque e defesa a fim de que se sustente a tensão do desafio e se crie um núcleo de disputa entre as equipes tendo como condicionante a bola.

Nesse plano, há vários outros elementos que, em conjunto, dão uma forma mais específica à configuração da disputa típica desse ou daquele esporte coletivo, determinando os limites constituintes às unidades interativas e às condições para a formação de um resultado justo, compondo, assim, todo o sistema prático do esporte em questão. Entre esses elementos temos: número de jogadores; tamanho do campo; tempo para a ação; áreas que podem ou não ser ocupadas, em que momento, por quanto tempo; contatos permitidos e não permitidos; movimentos que as equipes e jogadores podem ou não podem fazer; condições de condução da bola; restrições quanto aos níveis de agressividade permitidos; punições disciplinares com a função de proteger a prática de boa-fé e o jogo limpo.

Essa experiência prática, entretanto, só é compreendida se considerarmos a relação desses desafios interativos imediatos com o objetivo do jogo: obter ao fim da partida um saldo de pontos superior ao do adversário, alcançando-se o reconhecimento da vitória. Nos jogos agonísticos deve haver alguma relação de mérito entre a pontuação e as competências postas à prova no jogo. Assim, para se alcançar a meta, é necessário o exercicio de um conjunto de habilidades consideradas importantes e a realização desses feitos (o gol, a cesta, o touch down) deve se converter em pontos. É preciso ligar de maneira justa o que se passa na sucessão das interações a posições oficiais na relação competitiva expressa em uma espécie de objetivação numérica "oficial" da relação competitiva, o placar, que, por sua vez, deve expressar uma relação mais ou menos justa ao final entre quem foi melhor, quem obteve mais pontos e venceu.

A conexão entre constituição da interação, o andamento da relação competitiva e a construção do resultado nos volta para a compreensão da forma transcendental do jogo como um todo.

\section{A ordem transcendental das interações}

Como a forma da unidade interativa organiza os esportes coletivos nessa linha temporal? Em sua forma lógica a partida apresenta sempre um sentido imediato e contínuo de movimento sequencial em uma série invariável: lataque equipe A versus defesa equipe B] $\rightarrow$ [rápida transição (para defesa) A versus rápida transição (para o ataque) $B] \rightarrow$ [defesa equipe A versus ataque equipe B]. A unidade interativa se encerra com a conclusão da ação coletiva ofensiva à meta ou com sua interrupção com a troca da posse da bola. Segue-se então um novo recomeço de outra unidade interativa, com os papéis de atacante e de defensor trocados entre as equipes, havendo um breve momento que os praticantes chamam de transição em que se preparam para a nova situação.

Na simultaneidade, a forma competitiva desses esportes determina que as disputas transcorram funcionalmente em correspondências mútuas, em ações contínuas e simultâneas: se um lado está atacando (isto é, se está tentando alcançar a meta, avançando no campo de jogo), o outro defenderá (ou seja, tentando impedir que o oponente consiga seu objetivo fechando espaços no campo de jogo). Na sucessão, há a alternância na ocupação da posição de atacante e de defensor, que coordena a disputa conferindo às ações no tempo complementaridade, funcionalidade e referência mútua frontal, acirrando o sentido de competição. Deve haver, tanto no plano da simultaneidade, quanto no da sucessão, um equilíbrio entre o que cada equipe possa fazer em relação a outra, em termos de ataque ou de defesa, para que se sustente movimento, envolvimento e adesão em cada lance. 
Em cada esporte, a unidade interativa se especifica em seus contornos. Em alguns esportes, há demarcações formais mais rigidamente determinadas: no basquetebol com o limite de 24 segundos e no voleibol com o limite de 3 toques na bola. Nesses esportes há um limite regulamentar à continuidade da ação coletiva de ataque que determina o fim da unidade interativa. Em outros, ela fica a cargo da própria disputa, como no futebol, onde a posse da bola é mais dificil de manter, caso em que o conjunto das regras constitutivas prescinde de limite para que haja sucessão de unidades interativa e alternância de posições.

\section{A imanência surgindo da transcendência: o núcleo gerador das disputas}

Vale frisar, entretanto, que o que ocorre na imanência das disputas não é determinado inteiramente pelo que se define pela forma transcendental constituinte. O movimento e o repouso, velocidades e lentidões dos movimentos e o sentido microscópico das ações nascem endogenamente das disputas, de pessoas reais jogando, isto é, agindo umas em relação às outras, em um ambiente próprio, em situações únicas, ainda que dentro da lógica do jogo. A duração de cada partida, das unidades interativas e da sua sucessão, isto é, o ritmo de cada partida, define-se no plano da realidade concreta, da imanência das disputas.

O núcleo gerador de toda a competição se refere à disputa entre atacantes e defensores ao redor da bola e envolve aquele que a detém, bem como os defensores e os atacantes circundantes. O que ocorre neste momento é decisivo em relação à continuidade da disputa, se permanecerão na posição de atacante e defensor ou se haverá troca. Esse núcleo, no entanto, não é o único nem tampouco o único a ser decisivo: ele influencia todas as demais interações em outros núcleos que desse raio se estendam a outras áreas do campo de jogo, mas também é influenciado por eles, pois são todos solidários, interdependentes e reciprocamente orientados em seus movimentos de conformação de ações coletivas de ataque ou de defesa.
Por isso, é importante ter em mente que todos esses núcleos formam uma só totalidade espacial, conformam um mesmo complexo interativo, estão em uma mesma sucessão temporal total de eventos. Esses outros núcleos, ocupando outros polos do complexo e sendo fundamentais para a continuidade da cadeia da ação coletiva, também ordenam aquele núcleo central. As posições mesmas entre núcleos centrais e periféricos se alternam com o deslocamento da bola.

Os jogadores se situam nesses núcleos compreendendo a conexão que as formas padronizadas e amplamente conhecidas entre membros competentes estabelecem entre eles. Esses jogadores acabam por se dispor a realizar ações coordenadas, integrando esses núcleos enquanto agem prospectivamente antecipando as ações uns dos outros, perseguindo o desafio do jogo. As ações coletivas então evoluem dentro do que as formas ou esquemas compartilhados de ação possibilitam, ora unificando ora dispersando núcleos de disputa. Tais movimentos seguem, portanto, padrões referenciais mais ou menos bem demarcados pelas mesmas formas tipicas, familiares e identificáveis com as quais os jogadores veem os desafios e agem.

O movimento real é sempre imanente, resultando do que os jogadores conseguem efetivamente fazer na gestão da disputa, ou seja, da força ou resistência que consigam impor uns aos outros e da contingência. Assim como esse movimento real também depende da gestão regulamentar da partida por parte de um árbitro, que se pretende imparcial, mas que é suscetivel às forças das circunstâncias, aos afetos intensos e às suas limitações perceptivas. Enfim, jogar é estar na iminência da imanência. Os jogadores recriam configurações, definem avanços e recuos com suas ações, os árbitros administram a agressividade, acertam e erram aqui ou ali. As expectativas e os sentidos das ações são sempre especificados e reespecificados em razão do que se passa dentro da partida. As linhas de força humanas que fazem cruzar o campo de jogo são atualizadas, tudo resultando da imanência das disputas vividas na partida sobre a transcendência constituinte do jogo. 


\section{A transcendência e a imanência da} ordem das relações

Para compreender o jogo como capaz de gerar uma partida envolvente do início ao fim, devemos entendê-lo em uma ordem de atividade que envolve, além da dimensão mais imediata das interações, outra, voltada a uma dimensão temporal mais alargada da partida. Esse aspecto da ordem se refere justamente à definição de posições na relação competitiva: quem está na frente ou atrás, quem está ganhando ou perdendo. Essas são referências fundamentais para a atualização do desafio. Ao modo como o jogo transcendentalmente organiza o encontro nessa dimensão chamo ordem das relações.

A partir da formalidade do jogo, constitui-se uma realidade de um tempo mais alargado, resultado do modo como a sucessão dos eventos interativos se produziu e de como foram sintetizadas as impressões deixadas até ali, gerando a percepção imediata das forças em confronto. Esse acúmulo resulta em modulação da tensão causada pelas disputas reais em face do propósito de vencer de cada uma das equipes, impregnando o ambiente, apresentando como orientação prática o sentido de igualdade ou superioridade de uma equipe em face da outra.

Vimos acima que a objetivação numérica "oficial" da relação competitiva deve expressar uma relação justa entre quem foi melhor e quem obteve mais pontos e venceu. Assim, a comparação entre o número de pontos concorre para uma definição justa de quem está em vantagem e em que proporção. O sistema de pontuação visa justamente quantificar oficialmente a vantagem ou a desvantagem de uma equipe em relação à outra a partir do número de vezes que objetivamente conseguiu alcançar a meta. O modo como essa pontuação se acumula, traduzindo vantagem em pontos, instaura um plano das relações em que a zona intersubjetiva ganha profundidade temporal, sintetizando a relação inteira até ali, atualizando o desafio a cada situação.

A forma temporal dessa disputa faz com que, a partir da repercussão da sintese dos eventos uns sobre os outros, em sucessão, as coletivida- des apresentem suas supostas potencialidades essenciais vivas e manifestas nos seus feitos, gerando de imediato a afecção pelas forças em ação. Essas forças imanentes impregnam e constituem a zona intersubjetiva dos jogadores e correspondem a um espaço de posições sob uma lógica que organiza o que se passa entre os jogadores, determinando a posição de cada equipe em relação à adversária, de onde se experimenta o desafio da competição, agora.

Em cada sistema de pontuação próprio de cada forma competitiva, diferem o que deve ser feito para se alcançar a meta e em que proporção numérica, variável ou não, para poder se manifestar no placar. Quanto mais diversas as formas e as proporções de pontuação e mais frequentes as possibilidades de alcance das metas, mais minuciosa e potencialmente justa pode ser a expressão quantitativa do quão melhor é o melhor e do quão pior é o pior. Essa objetivação numérica pode ser também mais fiel caso façam repercutir sobre o encontro quesitos relevantes à manutenção da forma da prática como, por exemplo, o número de faltas e outras contagens paralelas do gênero que preservem o jogo limpo, punindo, na justa medida do desvio, os que não o sigam e inibindo os excessos de agressividade que a descaracterizariam.

A dinâmica do jogo no tempo, resultante da tensão entre uma equipe que busca reduzir a desvantagem e outra que tenta mantê-la ou ampliá-la, é dependente das diferenças nas proporções dos valores possiveis de pontuação, que estrutura o horizonte vivido no agora em relação ao fim da partida. O que há a se fazer no tempo disponivel para superar a diferença, isto é, o desafio presente no horizonte, depende, portanto, de como o sistema de pontuação estruturou a situação na sucessão (no sentido do que é ou não possivel alcançar em termos de pontuação em pouco tempo) e, assim, de como estruturou toda a competição. Mas se essa ou aquela equipe fez ou fará o que deve ser feito diante da resistência da outra a tempo para vencer, dependerá do que conseguiram ou consigam fazer no curso interativo imanente das disputas no exercício de suas competências. 
O desafio coletivo gerado e o forte sentido agonístico dos esportes coletivos tendem a mesclar ou fundir na experiência prática sentidos e afetos individuais em sentidos e afetos coletivos. Nossas forças individuais ressoam e compõem a força coletiva de nossa equipe, que emerge frente à da adversária. Há uma dinâmica de formação e de sintese dessas forças que nos afeta mostrando sua presença e, com isso, as forças de ambas as equipes emergem uma frente a outra, em uma tensão constitutiva da substância dessa realidade.

É na imanência da partida real, em face das impressões deixadas pelos feitos nas disputas concretas que essa força e presença coletivas evidenciam algo diferente da simples soma desses jogadores. No transcorrer da partida, consolida-se a percepção de uma força coletiva suis generis, supostamente essencial, própria daquela equipe ou daquela agremiação representada por aquele time, que parece assim se exteriorizar, impactando-nos e revelando-nos a nós mesmos em face do oponente, que também se mostra diante de nós. Revelação que é, ao mesmo tempo, uma revelação e uma construção ativa de um nós mesmos.

\section{Considerações finais}

No início desse artigo, mencionamos Elias e Bourdieu como referências muito presentes na produção acadêmica na área da sociologia do esporte. Não se pretende aqui negar a importância da sociogênese do desporto e a sua relação com mudanças configuracionais da sociedade moderna, com o advento do estado e com suas implicações civilizacionais em termos de uma nova dinâmica das pulsões; nem tampouco negar a relação institucional do campo esportivo com a sociedade de classe, os mecanismos de distinção e de dominação, as afinidades com disposições incorporadas e suas associações simbólicas, reflexo de estruturas sociais estruturadas e estruturantes. Como disse, essas abordagens revelam aspectos importantíssimos do fenômeno esportivo.

$\mathrm{O}$ que se pretendeu com o presente artigo foi apontar para outras possibilidades teóricas que ampliam nossos conhecimentos acerca do fenômeno esportivo enquanto fenômeno social microscópico. Procurei enfocar e orientar nosso foco para a ação e para certos aspectos do que se passa com os jogos esportivos a partir da experiência ativa e consciente dos jogadores, algo que as abordagens de Elias e de Bourdieu não fazem ao manter nosso olhar, por assim dizer, preso nas macroestruturas sociais.

Nesse sentido, o que destaquei aqui a partir da contribuição da fenomenologia e da etnometodologia foi o jogo como mundo vivido, como construto humano, resultado da teia de conexões entre uma ordem transcendental e de uma ordem imanente do jogo tecida pelos praticantes. Identificamos a relação de determinação recíproca entre ambas sob a forma de uma mesma organização prática de um mesmo mundo.

Assim, podemos compreender, por um lado, como a constituição da interação esportiva, o andamento da relação competitiva e a construção do resultado de uma partida manifestam a relação entre a forma transcendental do jogo e a ordem endógena dos eventos - um não se esgotando no outro, mas sempre interdependentes - como parte do mesmo; e, por outro lado, como essa organização fundamental se especifica concretamente em cada jogo esportivo por um conjunto particular de regras que é constitutivo de cada jogo esportivo (e seu mundo) e que contemplam certas pré-condições para a existência factual desses jogos como partida.

$\mathrm{Na}$ base dessa construção, temos os traços de uma forma básica e transcendental do jogo esportivo, que também podem ser compreendidos a partir de relações de determinação pré-ontológicas e como parte de uma gramática profunda inerente aos "jogos esportivos coletivos" que conhecemos. Essas pré-condições admitem diversas possibilidades na articulação de vários elementos em uma forma prática, cuja ontologia se caracteriza por um sistema prático mais específico, resultado da experiência prática, que identifica cada esporte e que estrutura mundos próprios, possibilitando sempre novas experiências agonísticas únicas.

Em todas essas formas existentes, os jogos esportivos coletivos proporcionam essas experi- 
ências extraordinárias, excitantes, integradoras e autênticas. É para isso que suas regras adquirem certa estabilidade, para reproduzir essas experiências. É nessa medida que a forma transcendental depende da experiência imanente para se constituir com tal potencialidade. É devido a essa relação entre ordem transcendental e ordem imanente que uma partida desenvolveu a capacidade de manter os jogadores sob o efeito aderente do seu visgo, sob uma espécie de força centripeta que os ata à atividade, que os aproxima, integrando cada um a seu ser mais próprio, a si mesmo, seu corpo, aos demais, aos objetos e ao espaço, à sua equipe, ao nosso time e ao deles, em uma experiência envolvente, íntegra, profunda e contínua, no espaço e no tempo vivo e factual de nossa partida.

Assim, o jogo em geral e o jogo esportivo em particular exibem sua capacidade de condensar a vida nos seus limites, em um mundo reduzido, simplificado, preparado para sermos com outros em uma relação sintética e intensificada. Nesse mundo, se acentua o próprio caráter de desafio presente na existência humana, determinando-se uma correspondência mais estrita entre competências, fins e meios, radicalizando polarizações, totalizando-as e encerrando-as na relação lúdica e agonística do ser jogador com o mundo desafiador do jogo.

Por essa razão, o jogo, além de poder ser compreendido em si, também pode ser visto - como tantos autores o fizeram, de Freud a Bourdieu, de Wittgenstein a Saussure - como uma espécie de laboratório onde se podem desvelar aspectos da existência humana que nele se ressaltam, mostrando-se particularmente visiveis pela perspectiva teórica aqui proposta.

\section{Referências}

Bourdieu, Pierre. 1983. Como é possivel ser esportivo? In Questões de sociologia, organizado por Pierre Bourdieu, 136-163. Rio de Janeiro: Marco Zero.

Bourdieu, Pierre. 1987. Pour une sociologie du sport. In Choses dites, organizado por Pierre Bourdieu, 203-216. Paris: Minuit.

Bourdieu, Pierre. 1990. The logics of practice. Stanford: Stanford University Press.
Bourdieu, Pierre. 2002. O poder simbólico. Rio de Janeiro: Bertrand Brasil.

Bourdieu, Pierre. 2007. A distinção: critica social do julgamento. São Paulo: Edusp.

Caillois, Roger. 1994. Los juegos y los hombres, la máscara e el vértigo. Mexico: Fondo de Cultura Económica.

Dewey, John. 1974. Textos selecionados. Coleção Os Pensadores. São Paulo: Abril.

Elias, Norbert e Eric Dunning. 1992. A busca da excitação. Lisboa: Difel.

Elias, Norbert. 1993. O processo civilizador. A formação do Estado e civilização, vol. 2. Rio de Janeiro: Zahar.

Elias, Norbert.. 1994. O processo civilizador. Uma história dos costumes, vol. 1. Rio de Janeiro, Zahar.

Garfinkel, Harold. 1963. A conception of, and experience with, 'trust' as a condition of stable concerted actions. In Motivation and social interaction: cognitive determinants, organizado por O. J. Harvey, 187-238. New York: The Ronald Press Company.

Garfinkel, Harold. 1967. Studies in ethnomethodology. New Jersey: Englewoods Cliffs.

Garfinkel, Harold. 2002. Ethnomethodology's program: working out Durkheim's aphorism. Boston: Rowman Littlefield Publishers.

Gurwitsch, Aron. 1957. Théorie du champ de la conscience. Paris: Desclée de Brouwer.

Gurwitsch, Aron. 1979. Human encounters in the social world. Pittsburgh: University Press.

Heidegger, Martin. 2005. Ser e tempo, parte 1. Petrópolis: Vozes

Latour, Bruno. 2012. Reagregando o social. Uma introdução à teoria do ator-rede. Salvador: Edufba.

Schutz, Alfred. 1967a. The phenomenology of the social world. Evanston: Northwestern University Press.

Schutz, Alfred. 1967b. Collected papers I: the problem of social reality. The Hague: Martinus Nijhoff.

Wittgenstein, Ludwig. 1996. Investigações filosóficas. Coleção Os Pensadores. São Paulo: Editora Nova Cultural.

\section{Eduardo Fernandes Nazareth}

Doutor em Sociologia pelo Instituto de Estudos Sociais e Políticos (lesp-Uerj), Rio de Janeiro, RJ, Brasil; professor da Fundação de Apoio à Escola Técnica do Estado do Rio de Janeiro (Faetec), Rio de Janeiro, RJ, Brasil. 